\title{
The Kangaroo Island bushfires of 2007 A meteorological case study and WRF-fire simulation
}

\author{
$\underline{\text { M.Peace }}^{\text {abc }}$, T.Mattner $^{\mathrm{a}}$, G. Mills ${ }^{\mathrm{a}}$ \\ ${ }^{a}$ School of Mathematical Sciences, Adelaide University \\ ${ }^{\mathrm{b}}$ Bureau of Meteorology \\ ${ }^{\mathrm{c}}$ Bushfire CRC \\ Email: M.Peace@bom.gov.au
}

\begin{abstract}
:
In December 2007, Kangaroo Island was set ablaze by numerous dry lightning strikes. Our research into the event has been conducted in two parts; a case study investigating the interactions between the local meteorology and observed fire behaviour, followed by simulations using the coupled atmosphericfire behaviour model WRF-fire. The findings from the case study highlight the importance of including information on atmospheric instability and spatial variation in meteorological parameters in fire weather forecasts. Our preliminary simulations using WRF-fire have explored the ability of the model to capture phenomena observed in the case study.

The case study identified two occurrences of unusual fire behaviour which have been simulated: the first, when a fire located in a local sea breeze front convergence zone produced a spectacular convection column which developed by release of potential atmospheric instability triggered by local lifting; the second, when unprecedented fire behaviour was observed in relatively benign conditions, hypothesised to be due to convective plume entrainment of dry air aloft, enhanced by topographically driven processes and very dry, open structured fuels.

The circumstances leading to the unusual fire behaviour(s) illustrate known limitations in the current Australian approach to fire weather forecasting, which neglects temporal and spatial variations, three dimensional atmospheric evolution and any interaction of the fire with the atmosphere.

We used the coupled atmosphere-fire model WRF-fire to simulate the fires, with the initial aim of running WRF-fire on an Australian event and subsequently to assess the ability of WRF-fire to simulate the vertical dynamics and fire-atmosphere coupling observed in the case studies.
\end{abstract}

Keywords: Bushfire meteorology, Kangaroo Island, fire-atmosphere feedback, WRF-fire. 


\section{INTRODUCTION}

This paper describes meteorological aspects of the 2007 Kangaroo Island bushfires and the results of preliminary simulations of the event using the coupled Weather Research and Forecasting and fire model WRF-fire. As meteorologists, our interest is in the influence of weather in fire environments, and our current focus is improving understanding of the role of vertical and dynamical atmospheric structure in driving fire behaviour. In order to achieve our objectives, we prepared a case study on the 2007 Kangaroo Island bushfires and identified occurrences of atmospheric dynamics impacting fire behaviour (Peace and Mills, in press). Subsequently, we ran WRF-fire with two aims; to firstly run the model on an Australian event and secondly, to see if WRF-fire could reproduce certain features we saw in the case study.

The veracity of the Australian fire danger ratings system is the subject of topical discussion, due largely to bushfire events in the past decade which have had a devastating impact on our community. These include (in no particular order and not intended as a comprehensive list); the Wangary fires of 2005, in which nine people lost their lives; the Canberra fires of 2003, which generated a pyro-tornado and destroyed hundreds of homes; the 2003 Eastern Victorian bushfires and the Victorian Alpine fires complex of 2006-2007, both of which burnt over 1 million hectares; the 2007 Boorabin fires in Western Australia, where three people lost their lives; and the cataclysmic Black Saturday fires, which devastated the state of Victoria in a single day. In addition to bushfire events, land management organisations across Australia embark on a seasonal regime of fuel reduction burns. Accurate weather information is essential to ensuring the objectives of these burns are achieved, while simultaneously minimising undesired impacts such as fire escapes and smoke haze. Organisations and individuals involved in fire management operations for both bushfires and fuel reduction burns have identified the requirement for an updated fire danger rating system in order to enable best practice decisions to be made. Relevant weather information is an essential input to a new system.

For several decades, Australian fire danger indices have been calculated using the McArthur rating systems for forest and grassland. The McArthur system was developed by analysis of results from numerous (mostly experimental) burns in the 1960's. The system encapsulated the pinnacle of bushfire science in Australia at its time of development, and has not been surpassed since. It is comprehensive and easy to understand and uses readily available information. However, the McArthur rating scale was based on small fires, burning under relatively benign conditions, and due to unprecedented bushfire events in recent fire seasons, the scale has been extrapolated well beyond its original scientific range into severe, extreme and catastrophic categories. That this extrapolation has occurred demonstrates that, in order to facilitate the greatest possible efforts to protect life and property, information is required beyond that provided by the McArthur system. What is currently limited, is comprehensive understanding of the way in which meteorological processes underpin the evolution of fires. This knowledge is required in order to anticipate the way in which the dynamic, three dimensional atmosphere will affect fire behaviour.

In order to explore how the atmosphere influences fire behaviour, we prepared a case study of the 2007 Kangaroo Island bushfires. The study found some interesting features in the vertical atmospheric structure at times when unusual fire behaviour was observed. These features include sea breeze convergence, topographic effects combined with heavy fuel loading, potential atmospheric instability realised by fire energy, dry air entrainment, low level wind profiles and atmospheric boundary layer stability. These features have also been documented by others; Mills (2005) describes cases of dry air entrainment, Hanley et al. (2005) describes the interaction between a wildfire and a sea breeze front, Sharples (2009) describes the ways in which topography affects fire behaviour and Fromm et al. (2006) document a dramatic pyro-convection incident. All these studies comprise a body of evidence illustrating why a complete fire weather forecast must include elements beyond near surface temperature, humidity and wind.

Subsequent to the meteorological case study of the Kangaroo Island fires, our interest turned to whether the phenomenon we observed could be captured in a coupled fire behaviour model. We took this approach because we believe that fire behaviour models have an important contribution to make in improving fire (weather) forecasting techniques. For this study, our aims were to firstly run WRF-fire on an Australian event, and then to examine whether the coupled model was successful in capturing the vertical atmospheric structure and fire behaviour seen in the case study. 
WRF-fire is the successor to the CAWFE model, described in Clark et al. (1996), in which the role of coupling in fire-line dynamics was also shown. The algorithms for fire spread and fuel combustion in WRF-fire are based on the model of Rothermel (1972) using the fuel descriptors of Anderson (1982). For Australian readers familiar with McArthur's model, but not acquainted with Rothermel's, it is useful to consider how the two differ conceptually. Both Rothermel and McArthur provide empirically-based equations for calculating fire spread. However, their approach differs in that Rothermel placed a greater emphasis on combustion and fuel arrangement, whereas weather parameters dominate in McArthur's meters. It is therefore somewhat surprising (particularly to an Australian meteorologist used to preparing fire weather forecasts) that Rothermel's equations for fire spread (and hence WRF-fire) have no dynamic dependence at all on temperature or relative humidity and fuel dryness is input as a constant.

Similarly, the treatment of wind in WRF-fire is worth noting. The wind coefficient in Rothermel's fire spread formula is derived from experimental results from burning fine fuels. The coefficient takes the form of a power function, strongly dependent on fuel particle surface to volume ratio. Fire spread using the Rothermel equations was much too fast in our simulations, as was found by Dobrinkova and Jordanov (2010) and Beezley et al. (2010).

Mandel et al. (2011) provide a comprehensive and current description of the WRF-fire physical model, the numerical algorithms used, the software structure and future development plans for the model. They note that the model is still under development and that although WRF-fire has been used for several real simulations, a larger set of case studies is required in order to validate the model. Mandel et al. (2011) also point out that WRF-fire uses WRF in a regime it was not designed for, resulting in a discontinuity between the scale of the fire processes (order of meters) and the atmospheric processes (order of kilometres) and that the global grids for topography and landuse distributed with the WRF pre-processing system are too coarse for high resolution fire modelling.

In this paper, we provide a brief overview of the Kangaroo Island case study, then report on our preliminary simulations using WRF-fire. The condition we wish to test is “... does the physical representation of vertical processes, coupling and fire spread in WRF-fire reproduce the fire behaviour and fire-atmosphere interactions observed in the Kangaroo Island case study?". Our planned future simulations will refine those presented here, by inclusion of higher resolution topography and vegetation data.

\section{THE 2007 KANGAROO ISLAND BUSHFIRES}

In December 2007, dry lightning strikes ignited numerous bushfires on Kangaroo Island. Four of the fires continued to burn for a two-week period, consuming over $20 \%$ of the island's vegetation. Suppression efforts were hampered by inaccessible terrain and tinder dry fuels and dense vegetation of the island's national parks and wilderness areas. Our case study of the event describes three days of interesting meteorology, two of which have been simulated with WRF-fire and are summarised below. Further detail and graphics are contained in the case study (Peace and Mills, in press).

On the 8th December, when four fires were actively burning, one fire located on the southeast corner of the island, near D'Estrees Bay was located in a convergence zone between the local onshore sea breeze and the synoptic northwesterly flow. The vertical atmospheric profile destabilised during the day, and combined with moist air in the sea breeze and heat from the fire, produced an environment conducive to vertical parcel motion. The smoke plume transformed into a dramatic convection column by realisation of potential instability. The evidence indicates that convective development occurred due to the process of FireCAPE, as described by Potter (2005).

On the 9th December, unprecedented fire behaviour was observed in relatively benign conditions. Early in the day, one of four active fires was burning near the southwest corner of the island, at the southern (down-valley) end of the largest river on the island, the Rocky River. Fanned by $35 \mathrm{~km} / \mathrm{h}$ southwest winds aligned with the valley axis, the fire accelerated through dry, dense fuels unimpeded to the head of the valley, where it shocked experienced fire crews with its ferocity. The activity is believed to have resulted from a combination of heavy, dry fuel, channelling of winds in the valley and the convective column of the fire entraining extremely dry air from above a low level subsidence inversion. Dry air entrainment causing unexpected fire behaviour has been described by Mills (2005), however it is believed the mixing mechanism in this case may have occurred due to vertical entrainment by the fires' convective column 
rather than (independent) atmospheric processes.

\section{WRF-FIRE SIMULATION SET-UP}

The WRF-fire model domain, physics and dynamics options for our simulations were determined by a combination of reference to Mandel et al. (2011), Dobrinkova and Jordanov (2010), Beezley et al. (2010) and Coen (2005), in addition to trial and error. We acknowledge our set-up may not be optimal.

WRF-fire was run in large eddy simulation and non-hydrostatic mode. The atmospheric grids contained six domains (main domain plus five nested domains), ranging from $30 \mathrm{~km}$ to $\approx 123 \mathrm{~m}$ in a $1: 3$ ratio, with 133 grid cells in $\mathrm{x}$ and $\mathrm{y}$ in the innermost domain. Time steps similarly followed a 1:3 ratio, ranging from 180 to $\approx 0.75$ seconds. Superimposed on the innermost nest, the fire-mesh had a 1:10 ratio, resulting in a fire mesh of $\approx 12 \mathrm{~m}$. 51 eta levels were specified in the vertical dimension. The model was initialised using 6 hourly GFS (Global Forecast System) data. Simulations were run for 24 hours, from a 1200UTC start in order to allow for model wind-up to be achieved by fire start time.

Physics options chosen were for full diffusion and using a prognostic equation for turbulent kinetic energy. Horizontal and vertical advection orders were set to 5th and 3rd respectively. Options were chosen to dampen horizontally and vertically propagating sound waves and external upper surface waves.

Fuel options were set to approximate the local mallee fuels, following data from McCaw (1997), Cruz et al. (2010) and McCaw (1998). The WRF-fire wind reduction factor value was selected in order to achieve fire spread approximating that depicted in Department of Environment and Heritage (2008) fire spread maps.

\section{Results}

Our goal of running WRF-fire on an Australian event has been successful. From the case study, there were two main atmosphere-fire coupling processes we hoped to reproduce using WRF-fire. The first was to examine whether the convection column of the Rocky River fire enabled dry-air entrainment from above the subsidence inversion. The second was to reproduce the potential instability, convergence and subsequent convection column development at the D'Estrees fire.

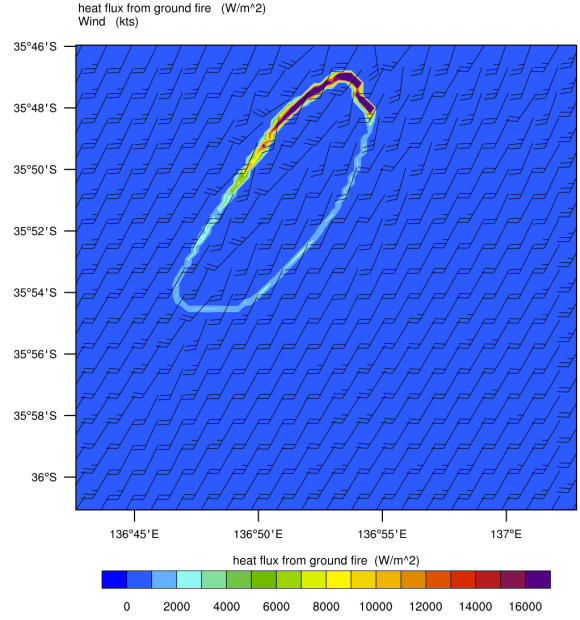

(a) Ground heat flux from the fire as a proxy for fire (b) perimeter and $10 \mathrm{~m}$ wind vectors at $0600 \mathrm{UTC}$.

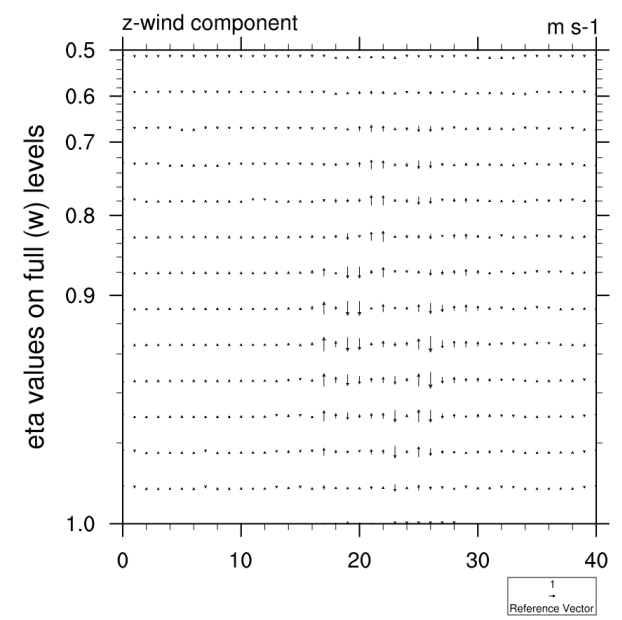

at 0600UTC.

Figure 1: Rocky River WRF-fire simulations

The Rocky River simulations exhibited fast fire spread in a fresh wind regime. Figure 1(a) shows several features worth noting, (1) an elongated spread area consistent with fire behaviour in strong winds, (2) 
greater fire activity on the (northwesterly) up-hill flank and (3) modified wind flow in the vicinity of the active fire front. Figure 1(b) shows vertical velocity in the fire area. It indicates vertical motion driven by fire convection reached approximately the level of the inversion (also supported by temperature and moisture profiles, not shown), thus suggesting dry air entrainment was possible. It is worth noting that the vertical velocity suggests a circulation with an ascending and descending arm closely located to the heat source. This direct circulation suggests that if dry air is present it can be mixed downwards in close vicinity to the fire front. The representation shown suggests the alternative mechanism for fire convection of an updraft compensated by broad scale down-motion (which would be less likely to mix sufficient dry air to produce a short term impact on fuel moisture) does not occur.
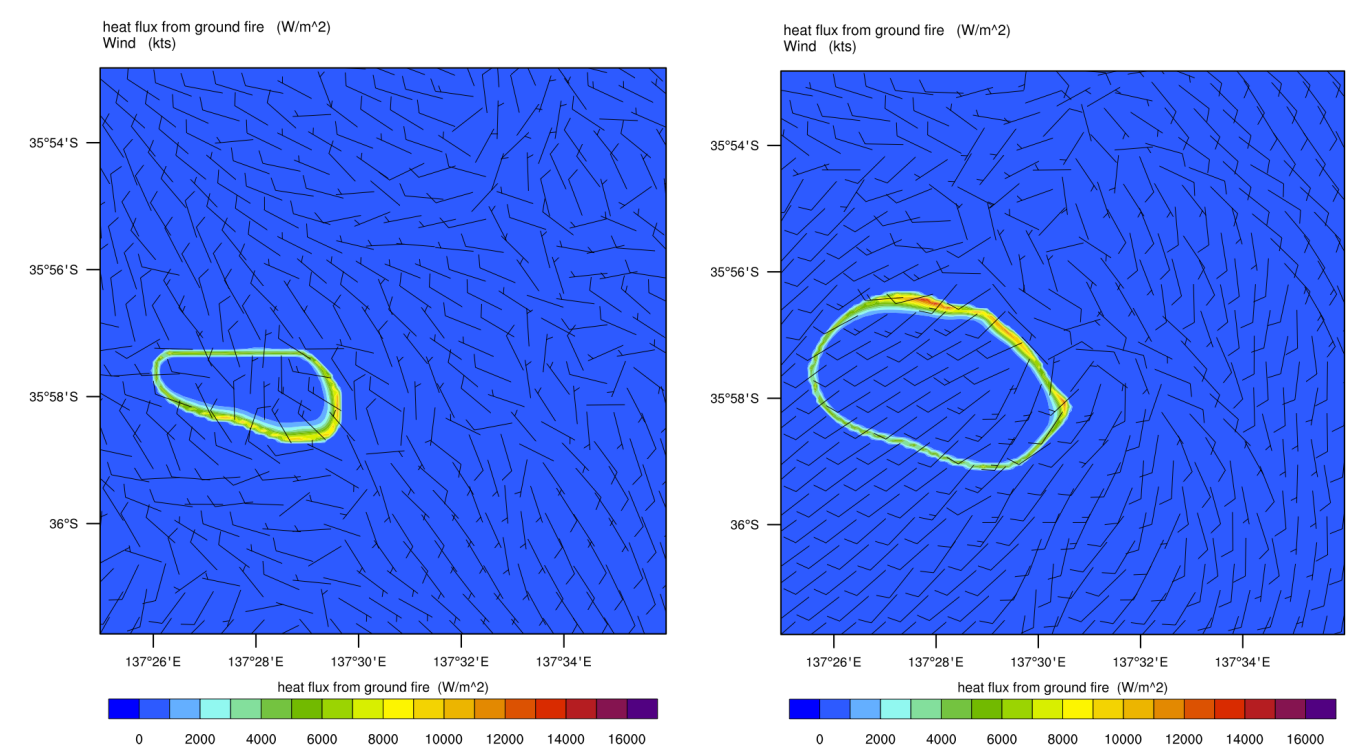

(a) Ground heat flux as a proxy for fire perimeter and $10 \mathrm{~m} \mathrm{(b)} \mathrm{Ground} \mathrm{heat} \mathrm{flux} \mathrm{as} \mathrm{a} \mathrm{proxy} \mathrm{for} \mathrm{fire} \mathrm{perimeter} \mathrm{and} 10 \mathrm{~m}$ wind vectors at 0130UTC

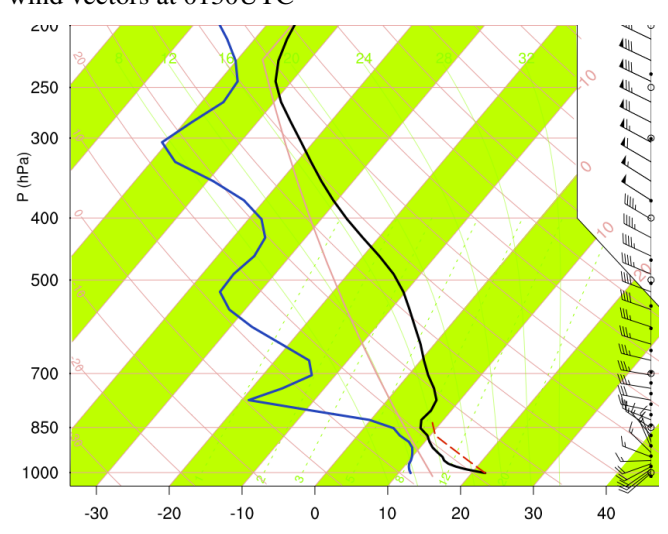
wind vectors at $0520 \mathrm{UTC}$

(c) WRF vertical profile of temperature and moisture at (d) $-35.98 \mathrm{~S} 137.5 \mathrm{E}$

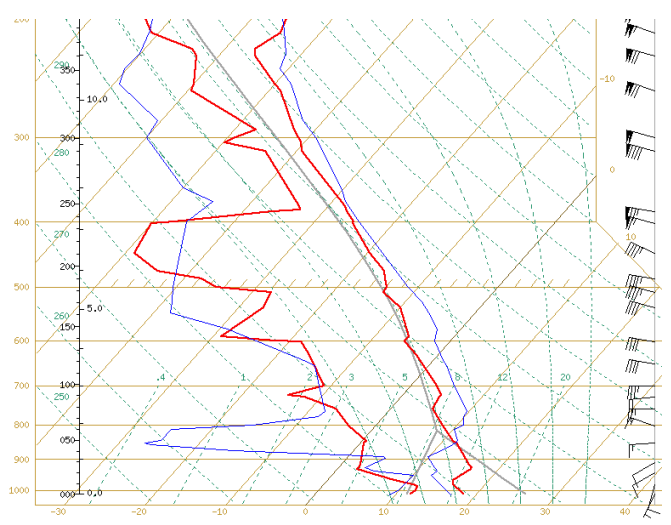

erved vertical profile of temperature and moisture at Adelaide airport at 08/12/2007 1200UTC (red) and 07/12/2007 1200UTC (blue)

Figure 2: D’Estrees Bay WRF-fire simulations

The D'Estrees simulations Figure 2(a) and Figure 2(b) show the response of fire spread to convergence and wind direction. Clearly apparent in the simulations was enhanced fire activity produced by subtle variations in wind. However, the deep convection column seen in the case study (which we had hoped to reproduce) was not evident, either in the vertical wind structure or by examination of tracer particles. This 
may be due to the inversion seen in 2(c), as compared to the observed vertical structure in Figure 2(d), alternatively the heat flux from our simulated fire may have been insufficient to generate vertical feedback.

\section{Discussion}

We have successfully simulated an Australian event using WRF-fire, and the results have provided valuable insights into our questions regarding fire-atmosphere coupling and current ability to reproduce observed phenomena by numerical simulation. Numerous aspects were simulated well, with output produced in near-real time, however more work needs to be done to establish how useful the results are to the fire management community. Our preliminary simulations have been with low resolution (approximately $1 \mathrm{~km}$ ) topography data, which is too coarse to resolve detail in the fire spread. In future simulations, we intend to (re-)run our current domains with modified Landuse grids, terrain following vegetation data and using 25m Digital Elevation Model grids.

Our vertical motion cross sections of the Rocky River fire simulations showed the convection column developed to the approximate height of the subsidence inversion, suggesting entrainment of dry air from above the inversion by fire convection was possible, however further evidence is required to conclusively demonstrate this. An absence of enhanced fire activity resulting from dry air entrainment is to be expected, as the fire equations in WRF-fire have no dependence on temperature or humidity and fuel dryness is input as a constant, not a dynamic parameter. As fuel moisture has a critical influence on fire behaviour (Mills, 2005), inclusion of dynamic fuel moisture by response to varying temperature and humidity in WRFfire is desired. Modifying the code to implement a fuel moisture value which changes with atmospheric temperature and humidity, is a conceptually simple premise and one we intend to pursue. This would extend the current coupling between the atmosphere and fire components of the model.

Our simulations of the D'Estrees fire did not show strong convection column development above the fire. Two reasons are proposed; the vertical profile over the fire ground showed a low level inversion that may have inhibited vertical development. Alternatively; the heat and moisture fluxes produced in our simulated fire may not have been of sufficient magnitude to generate vertical development (due to having a propagating fire line with a constrained active burn time). The lack of vertical development in our simulations provides an interesting contrast to the (idealised) WRF simulations of the 2003 Canberra bushfires by Cunningham and Reeder (2009), where vertical feedback resulted in tornadogenesis. It is interesting to note that the continuous heat and moisture fluxes in the Cunningham and Reeder (2009) simulation were an order of magnitude greater than those produced by WRF-fire in our simulation.

WRF-fire is still under development and model fidelity is expected to improve. Several planned improvements were mentioned in the introduction. We suggest one of the main advances required is refinement of the empirically based fire spread parameterisations. We used the wind reduction factor to slow fire spread (a reasonable approach as it effectively decreases the wind speed to the mid-flame height) however the choice of value is somewhat arbitrary. Two useful additions to WRF-fire for the Australian environment would be crown fires and spotting, both of which are major contributors to extreme fire behaviour in Australian bushfire events. Crown fires are highly likely to produce fire-atmosphere feedback due to their intensity. Spotting is a critical element of fire behaviour in Australian fuels, however due to its inherent nature a probability or stochastic approach would be required to represent the process.

The Kangaroo Island case study identified three occasions where vertical atmospheric structure played an important role in modifying observed fire behaviour. This event, in concert with other published case studies (see introduction), unpublished events and anecdotal evidence, shows that vertical atmospheric dynamics and feedback processes frequently and significantly impact bushfires and prescribed burns in Australia. This repeatedly manifests as fire behaviour that would not be anticipated by consideration of the surface weather elements temperature, relative humidity and wind alone. In light of this evidence it is clear that Australian fire weather forecasting should place greater emphasis on vertical atmospheric profiles, convergence zones, dry air entrainment and low level stability.

\section{REFERENCES}

Anderson, H. (1982). Aids to determining fuel models for estimating fire behavior. general technical report int-122. United States Department of Agriculture, Forest Service, Internountain Forest and 
Range Experiment Station.

Beezley, J., A. Kochanski, V. Kondratenko, J. Mandel, and B. Sousedik (2010). Simulation of the Meadow Creek fire using WRF-Fire. Poster at the AGU Fall Meeting 2010.

Clark, T., M. Jenkins, J. Coen, and D. Packham (1996). A coupled atmosphere-fire model: Convective feedback on fire-line dynamics. Journal of Applied Meteorology 35, 875-901.

Coen, J. (2005). Simulation of the Big Elk Fire using coupled atmosphere-fire modeling. International Journal of Wildland Fire 14, 49-59.

Cruz, M., S. Matthews, J. Gould, P. Ellis, M. Henderson, I. Knight, and J. Watters (2010). Fire dynamics in mallee-heath. fuel, weather and fire behaviour prediction in South Australian semi-arid shrublands. Technical report, Bushfire Cooperative Research Centre.

Cunningham, P. and M. Reeder (2009). Severe convective storms initiated by intense wildfires: Numerical simulations of pyro-convection and pyro-tornadogenesis. Geophysical Research Letters 36.

Department of Environment and Heritage (2008). Kangaroo Island fire complex fire spread maps. Fire Management Branch, Department of Environment and Heritage, South Australia. Provided by Mike Wouters.

Dobrinkova, N. and G. Jordanov (2010). WRF-Fire wildfire modeling in the test area of Harmanli, Bulgaria. In D. Viegas (Ed.), Geoscientific Model Development Discussions.

Fromm, M., A. Tupper, D. Rosenfeld, R. Servranckx, and R. McRae (2006). Violent pyro-convective storm devastates Australia's capital and pollutes the stratosphere. Geophysical Research Letters 33. LO5815.

Hanley, D., P. Cunningham, and S. Goodrick (2005). Interaction between a wildfire and a sea breeze front. In Proceedings of the East Fire conference May 2005 Sixth Symposium on Fire and Forest Meteorology.

Mandel, J., J. Beezley, and A. Kochanski (2011). Coupled atmosphere-wildland fire modeling with WRFfire. Geoscientific Model Development Discussions 4, 497-545.

McCaw, L. (1998). Research as a basis for fire management in mallee heath shrublands of south-western Australia. In D. Viegas (Ed.), 3rd International Conference on Forest Fire Research/14th Conference on Fire and Forest Meteorology, 16-20 November, Portugal.

McCaw, W. (1997). Predicting fire spread in Western Australian Mallee-heath shrubland. Ph. D. thesis, School of Mathematics and Statistics, University College, University of New South Wales.

Mills, G. (2005). On the sub-synoptic meteorology of two extreme fire weather days during the Eastern Australian fires of January 2003. Australian Meteorological Magazine 54, 265-290.

Peace, M. and G. Mills. A case study of the 2007 Kangaroo Island bushfires. Technical report, Australian Government Bureau of Meteorology. In press.

Potter, B. (2005). The role of released moisture in the atmospheric dynamics associated with wildland fires. International Journal of Wildland Fire 14, 77-84.

Rothermel, R. (1972). A mathematical model for predicting fire spread in wildland fires. USDA Forest Service Research Paper INT-115.

Sharples, J. (2009). An overview of mountain meteorological effects relevant to fire behaviour and bushfire risk. International Journal of Wildland Fire 18, 737-754. 